\title{
Mechanical Impedance of Cerebral Material
}

\author{
Moez Chakroun*, Hédi Ben Ghozlen \\ Materials Physics Laboratory, Faculty of Sciences of Sfax, Sfax University, Sfax, Tunisia \\ Email: *mchakroun1@yahoo.fr
}

Received January 14, 2012; revised February 15, 2012; accepted February 29, 2012

\begin{abstract}
The tentative variation of the mechanical impedance, of a cylindrical sample of cerebral material, has been achieved by Vibrometer Laser according to the frequency. The studied matter is supposed homogeneous, isotropic and stationary. A multilayered mechanical model has been associated to the studied sample to simulate its vibration. The theoretical expression of mechanical impedance has been determined while taking the mechanical/electric analogy as a basis. A good adjustment of theoretical model parameters permitted us to have a good agreement theory/experience of the mechanical impedance variation according to the sample vibration frequency.
\end{abstract}

Keywords: Vibrometer Laser; Mechanical Impedance; Viscoelastic; Cerebral Material; Model

\section{Introduction}

The head is part of the body most threatened by the fatal injuries in accidents. Brain injuries cause approximately 56,000 dead and 83,000 disabled in the United States each year [1]. The typical duration of loading in road accidents is between $1 \mathrm{~ms}$ and $50 \mathrm{~ms}$, according to the rigidity of the impacted area. This interval is approximately between $20 \mathrm{~Hz}$ and $1000 \mathrm{~Hz}$ frequency. It is therefore essential to carry out measures to the Interior of this frequency band. Because of the impossibility of technical and legal studies of human in vivo, they have been supplanted by studies in vitro performed in low proportion on humans [2-4], and largely on animals like pigs [5-8] and monkey [9-11].

The aim of this work is to develop a model to simulate the variation of the impedance mechanical ( $Z=$ force/ speed) material cerebral pork (viscoelastic materials [12]) on a range of frequency from $60 \mathrm{~Hz}$ to $580 \mathrm{~Hz}$. The studied material is assumed to be homogeneous, isotropic, and stationary.

\section{Method}

The sample mixture of substances grey and white taken within the cerebral cortex pig brain is cylindrical, diameter $d=2 \mathrm{~cm}$, height $h=3 \mathrm{~mm}$ and mass $M=1 \mathrm{~g}$. It is cut from using part takes precedence. It entails part allows cutting cylindrical samples by helical motion descent. This is a method commonly used in [13] soft tissue Biomechanics because it allows you to obtain a cylindrical geometry, uniaxial tests, allowing the hypothesis of a field of uniform and unidirectional constraint depending

"Corresponding author. on the axis of the cylinder. The sample is requested at its bottom surface with a sinusoidal force $F=F_{0} \exp (j 2 \pi f t)$ provided by a vibrating pot where the sample is deposited. The vibration solicitation is therefore a normal tension/compression type solicitation. This solicitation is own weight of the sample. A sensor force brought into contact with the vibrant plateau of the pot enables measurement of the force $F$ applied to the underside of the sample. The speed $v$ of top sample is measured by a speed sensor to laser. Treatment of experimental data by software MATLAB allows us to deduce the $F_{0}$ force as well as speed $v_{0}$ module.

\subsection{Experimental Device}

The experimental device (Figure 1) mainly includes a vibrant pot, a force sensor, a laser (helium neon) speed sensor and a computer with its acquisition Board (HPVEE). Note that experience was carried out ten times with samples taken from the same region (cerebral cortex), different, of the same dimensions.

\subsection{Modeling of the Mechanical Impedance}

To determine the theoretical mechanical impedance $Z$ th $=$ $F / v$ of studied system, we have associated the mechanical model to 5 channels (types Kelvin-Voigt) (Figure 2) that we used in 2009 [14] to characterize brain matter of pork in terms of modulus of elasticity and depreciation internal. The vibration of the sample is then equated with the vibration of 5 overlapping cylindrical layers on the other. Each layer is then height $h_{5}=h / 5$ diameter d and mass $m_{5}$ $=M / 5$.

To resolve the problem we have used the analogy of 


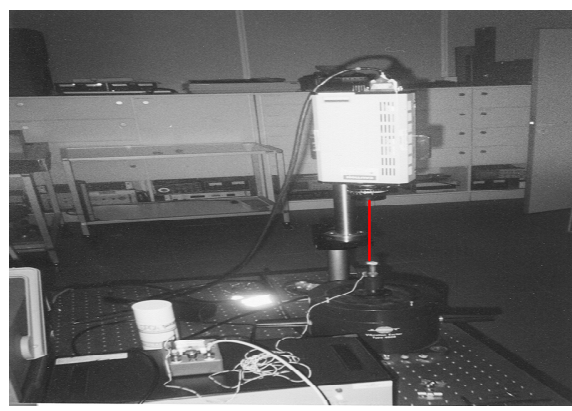

(a)

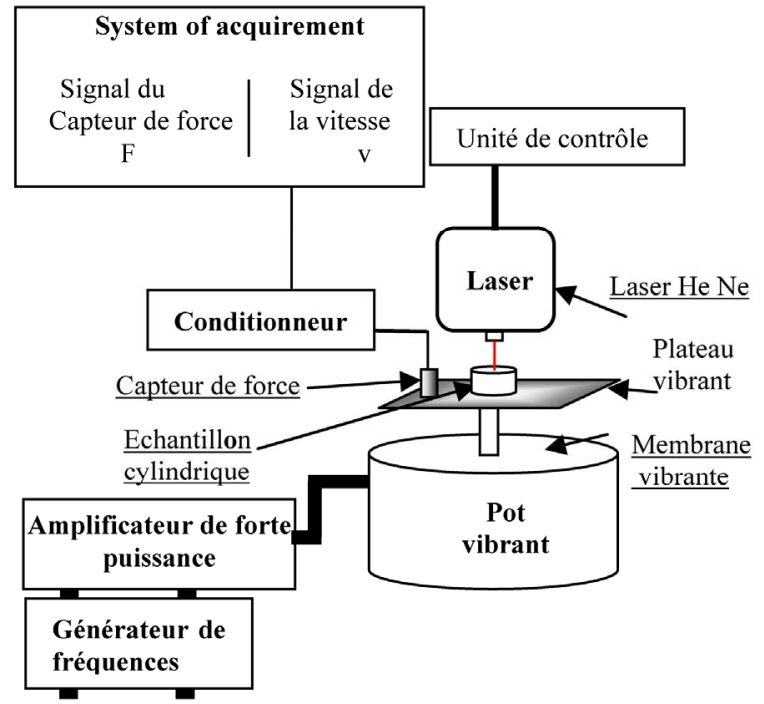

(b)

Figure 1. (a) The experimental device; (b) Diagram of the experimental device.

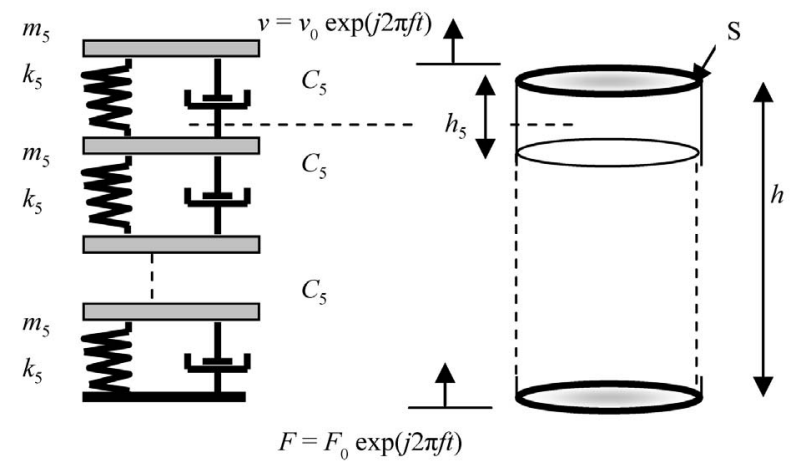

Figure 2. KV model [14].

mechanical/electrical (analogy force-voltage). Thus, our mechanical model was replaced by an electric model (Figure 3) with resistors $R_{5}$, inductances $L_{5}$ and capacitors $C_{5}$ :

In this circuit $V_{0}$ and $V_{5}$ represent the voltage input and output circuit respectively. $I_{0}$ and $I_{5}$ are input and output circuit intensities. Since then, studied mechanical system is excited a single endpoint (lower surface) that the

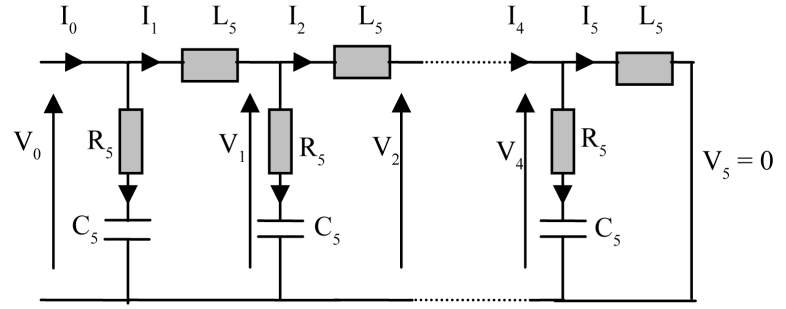

Figure 3. Electrical model analogous to our KV mechanical model.

other end (upper surface) is free (is not subject to any constraints), in this case, in our electric model output should be short-circuitée $\left(V_{5}=0\right)$. On this circuit transfer matrix is given by:

$$
[T]=\left(\begin{array}{cc}
1+\frac{Z_{5}}{Z_{5}^{*}} & -Z_{5}^{*} \\
-\frac{1}{Z_{5}} & 1
\end{array}\right)
$$

where $Z_{5}^{*}$ and $Z_{5}$ are the equivalent impedances to the inductance and the resistance in series with the capacity respectively:

$$
Z_{5}^{*}=j L_{5} 2 \pi f
$$

and

$$
Z_{5}=R_{5}+\frac{1}{j C_{5} 2 \pi f}
$$

Allowing us to write:

$$
\left(\begin{array}{l}
0 \\
I_{5}
\end{array}\right)=[A] \times\left(\begin{array}{c}
V_{0} \\
I_{0}
\end{array}\right)
$$

with $[A]=[T]^{5}=\left(\begin{array}{ll}A_{11} & A_{12} \\ A_{21} & A_{22}\end{array}\right)$

It follows that

$$
\left\{\begin{array}{l}
0=A_{11} V_{0}+A_{12} I_{0} \\
I_{5}=A_{11} V_{0}+A_{22} I_{0}
\end{array}\right.
$$

The two Equations (5) and (6) allows us to deduce that

$$
\frac{V_{0}}{I_{5}}=\left[A_{21}-\frac{A_{22} A_{11}}{A_{12}}\right]^{-1}
$$

By returning to our mechanical model (KV model) and taking into account the analogy mechanical/electrical, theoretical expression of the mechanical impedance $Z$ th $=$ $F / v$ can then be written as (7). Except that (2) and (3) and electrical impedance will be replaced by their mechanical analogues:

$$
Z_{5}=\alpha_{5}+\frac{k_{5}}{j 2 \pi f}
$$

and 


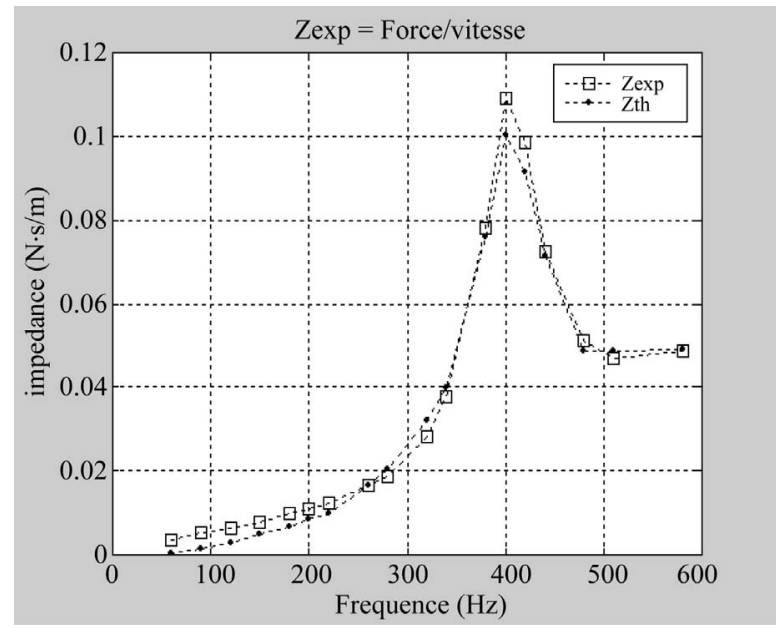

Figure 4. Superposition theory/experience of mechanical impedance modulus.

$$
Z_{5}^{*}=j m_{5} 2 \pi f
$$

\subsection{Determination of the Parameters of the Model}

By introducing the $k_{5}(f)$ values and $\alpha_{5}(f)$ already calculated in 2009 (Table 1) [14] we could calculate the values from the MATLAB software, and corresponding to each frequency of vibration of the sample. The module on $\mathrm{KV}$ model to 5 mass layers depending on the frequency theoretical mechanical impedance variation is then determined.

\section{Results}

The next curve represents the theory/experience the mechanical impedance module overlay.

From the Figure 4 we can see that the values of $k_{5}(f)$ and $\alpha_{5}(f)$ already determined in 2009 [14], model very well the mechanical impedance of the studied system.

\section{Conclusions}

Our model (5-layer mass) type Kelvin-Voigt, with variable parameters based on the frequency is very well to simulate changes in mechanical impedance module of cylindrical sample of pork brain tissue.

The theoretical mechanical impedance $Z$ th $=F / v$, that was used in this study, can be used in finite element model of brain to simulate the mechanical impedance.

This mechanical impedance represents a maximum in the surrounding of $400 \mathrm{~Hz}$. It means that deformation is maximal at this frequency.

So, we can note that this frequency vibration can cause damage on the brain tissue.

\section{REFERENCES}

[1] D. M. Sosin, J. E. Sniezek and R. J. Waxweiler, "Trends in Death Associated with Traumatic Brain Injury, 1979 through 1992," Journal of the American Medical Association, Vol. 273, No. 22, 1995, pp. 1778-1780. doi:10.1001/jama.1995.03520460060036

[2] G. Fallenstein, V. Hulce and J. W. Melvin, "Dynamic Mechanical Properties of Human Brain Tissue," Journal of Biomechanics, Vol. 2, No. 3, 1969, pp. 217-226. doi:10.1016/0021-9290(69)90079-7

[3] L. Z. Shuck and S. H. Advani, "Rheological Response of Human Brain Tissue in Shear," Journal of Basic Engineering, Vol. 94, No. 4, 1972, pp. 905-911. doi: $10.1115 / 1.3425588$

[4] F. Farmanzad, S. Najarian, M. R. Eslami and A. S. Seddighi, "A Novel Model for Biomechanical Behavior of Human Brain in Epidural Hematoma Injuries," Bio-Medicals and Engineering, Vol. 17, No, 2, 2007, pp. 119-125.

[5] K. L. Thibault and S. S. Margulies, "Age-Dependent Material Properties of the Porcine Cerebrum: Effect on Pediatric Inertial Head Injury Criteria," Journal of Biomechanics, Vol. 31 No.12, 1998, pp. 1119-1126. doi:10.1016/S0021-9290(98)00122-5

[6] D. Brands, "The Large Shear Strain Dynamic Behaviour of in Vitro Porcine Brain Tissue and a Silicone Gel Model Material," Stapp Car Crash Journal, Vol. 44, 2000, pp. 249-260.

[7] S. Nicolle, M. Lounis, R. Willinger and K. Bekkour, "Caractérisation et Modélisation du Tissu Cérébral de Porc," 27ème Congrès de la Société de Biomécanique, Valenciennes, 12-13 September 2002.

[8] S. Mehdizadeh, M. Khoshgoftar, S. Najarian and F. Farmanzad, "Comparison between Brain Tissue Gray and White Matters in Tension Including Necking Phenomenon," American Journal of Applied Sciences, Vol. 5. No. 12, 2008, pp. 1701-1706.

doi:10.3844/ajassp.2008.1701.1706

[9] L. E. Thibault, T. A. Gennarelli and S. Margulies, "Physical Model Simulations of Brain Injury in the Primate," Journal of Biomechanics, Vol. 23, No. 8, 1990, pp. 823836.

[10] L. E. Bilston, Z. Z. Liu and N. Phan-Thien, "Lineaire Viscoelactic Properties of Bovine Brain in Shear," Journal of Biorheology, Vol. 34, No. 6, 1997, pp. 377-385. doi:10.1016/S0006-355X(98)00022-5

[11] F. Farshad, M. Barbezat, P. Flüeler, F. Schmidlin, P. Grabe and P. Niederer, "Material Characterization of the Pig Kidney in Relation with the Biomechanical Analysis of Renal Trauma," Journal of Biomechanics, Vol. 32, No. 4, 1999, pp. 417-425. doi:10.1016/S0021-9290(98)00180-8

[12] C. W. Jamisson, R. Marangoni and A. Glaser, "Viscoelastic Properties of Soft Tissues by Discrete Model Characterization," Journal of Biomechanics, Vol. 1, No. 1, 1968, pp. 33-46. doi:10.1016/0021-9290(68)90036-5

[13] S. Park, R. Krishnan, S. Nicoll and G. Ateshian "Interstitial Fluid Load Support in Unconfined Compression," Journal of Biomechanics, Vol. 36, No. 12, 2003, pp. 17851796. doi:10.1016/S0021-9290(03)00231-8

[14] M. Chakroun, M. H. Ben Ghozlen, I. Elloumi and S. Nicolle, "Détermination du Module D'élasticité de la Matière Cérébrale," Compte Rendu Physique, Vol. 10, No. 23, 2009, pp. 236-241. doi:10.1016/j.crhy.2009.03.010 